\title{
Discussion: information technology
}

Christine Borgman

Tony Cawkell stated that there is little overlap between the communications and information technology disciplines, and bibliographically, there is very little cross-citation within these fields. It seems to be retrograde to continue in this way. New models are needed to pull these two together and reflect the change and flow in information. What should these new models be, to take advantage of the themes discussed here?

Tony Cawkell

A book to which I referred recently, the Handbook of Communication Studies, has between 5000 and 6000 references, but I could only find three that overlapped between the two fields, so it is still a problem.

Barry Mahon

My wife, who is a biochemist, said there is only one journal she reads, and that is Current Contents. The techniques for finding information are different now, but do scientists actually look any further than before? Are they still constrained to their research networks?

\section{Don King}

There was a 1960s associative retrieval model with indexes containig both terms and citations. This is a good model to re-employ as it includes the advantages of both. Does anybody know if it is being used anywhere now?

Eugene Garfield

I don't know, but there has been a great growth in the field: the emergence of the Web and linking through to documents should improve the ability to cross between fields and encourage cross-discipline citation.

\section{Christine Borgman}

I am wondering about the impact of real-time communication, and how we could now enhance our understanding of the process of scientific communication in light of this. Citation analysis takes years to complete, but we should take the opportunity to take real time communication into account in our studies.

\section{Eugene Garfield}

I don't think it will change our understanding. The time lag will be reduced, but the theoretical problems will remain. How do you get scientists to read other disciplines?

\section{Peter Burnhill}

Funded research activity and citations take research projects forward, but there has to be a certain time lapse before a flow of publications come from them. Scientists have to read the publications, use them to create research projects, do the research and then publish it. The overlying factor is one of patience, as 
time is required for the flow of information and for its impact to occur. There is too much emphasis on the "now".

There is also a difference between particular fields. Article- (and therefore citation-) based subjects such as psychology and economics tend to be more contemporary subjects. Other subjects, like history and anthropology, favour book-length work and are not currency-dependent. This may explain the popularity of citations in some areas more than others.

\section{Eugene Garfield}

In the case of materials less dependent on currency, bibliometrics are better for discovering communication processes, whereas information retrieval tools are of more use in contemporary fields.

\section{Mayur Amin}

In my experience, information scientists are actually the only ones who use information retrieval tools and bibliometrics. Scientists tend to look for familiar names in their research community when looking through the literature.

\section{Don King}

Most of the people reading journal articles are not authors of articles themselves, but they also need to be included in any analysis of information use. Studies should be undertaken to discover what they use the information for: whether it is to be kept up to date, or for research purposes. Have any studies been carried out on how the information is used by non-author users?

\section{Jennifer Rowland}

David Ellis at Sheffield University has been involved in studies relating to how researchers use literature.

\section{Tony Cawkell}

The timeliness of database information in journal articles is dependent on the delay between the date of acceptance of an article by a journal and the date on which the information in an article is made available to a database user. The Web of Science worked well for investigating speech recognition research up to about one year before the investigation's date. To find out about current work leading to the parity, or perhaps the superiority of the Dragon system over IBM's system. the Web provided some current information.

\section{Micheline Beaulieu}

Generally, this situation is not good, because it means that research will also suffer from being a year out of date and won't take into account recent information or materials. It is also interesting that the discussion so far has been on human behaviour, rather than the technology involved.

\section{Brian Shackel}

Through supporting many research students, I have formed a hypothesis about non-usage of information tools - and citation tools aren't used as much as information scientists would believe. It is very difficult to persuade Ph.D. students to do information searching at the start of their degree, but when they are writing up it is less difficult, because they recognise the need to get the information. In a similar way, researchers in new research areas don't want to know what has been done previously and that someone has already done it! The BLEND project as an electronic database was very specific and very good, but we just couldn't get people to use it. However, in an industrial or research environment, there is a need to make use of prior work in order to solve practical, time-limited problems that occur. In this case, people do use these tools. 


\section{Don King}

Picking up on a comment that Tony Cawkell made in his presentation: he stated that he could not see the Web being universal. I disagree. With the advent of digital TV that will have Internet access included, it will be opened up to a whole new market. If you look at the advert where the man catches a fish, takes a digital photo and transmits it to his friend via his mobile phone, they are using radio transmission, so there are two new markets for the Internet. The time when the Web becomes universal may be soon.

\section{Tony Cawkell}

What I meant when I said the Internet would not be universal was that it would never be available on a global scale. In the world as a whole, most people have never even used a telephone, so how can they get access to this sort of technology? Someone has to pay, but the average per capita earnings of half the world's population is around \$360 p.a., compared to over \$20,000 in the United States. 